\title{
Development of Microplitis bicoloratus on Spodoptera litura and implications for biological control
}

\author{
Kaijun LUO ${ }^{1,2}$, John T. TRUMBLE ${ }^{3}$ and Yi PANG ${ }^{1, *}$ \\ ${ }^{1}$ State Key Laboratory of Biocontrol \& Institute of Entomology, Sun Yat-Sen \\ (Zhongshan) University, Guangzhou, 510275, P.R. China; ${ }^{2}$ Agriculture Environment \\ and Resource Research Institute, Yunnan Academy of Agriculture Sciences, \\ Kunming, 650205, P.R. China; ${ }^{3}$ Department of Entomology, University of \\ California-Riverside, Riverside, CA 92521, USA \\ *Author for correspondence: e-mail:ls12@zsu.edu.cn
}

Received 11 March 2006; accepted in revised form 7 June 2006

\begin{abstract}
Microplitis bicoloratus Chen (Hymenoptera:Braconidae:Microgastrinae), a new species of Microplitis Förster from China, is a solitary endoparasitoid of the larvae of the cotton leafworm, Spodoptera litura (Fabricius) (Lepidoptera: Noctuidae). This parasitoid is the first to be successfully reared and evaluated in the laboratory as a potential agent for the biological control of S. litura in China. Oviposition, immature development, and the effects of parasitism on the development of $S$. litura were studied. In long-term oviposition trials, females laid eggs on $S$. litura larvae for up to 10 days; oviposition was heavily skewed toward the first few days, with approximately one third of the eggs laid on day 1 and over $50 \%$ laid by day 3 . This rapid oviposition rate increases the potential for biological suppression of host populations because the likelihood of mortality for the parasites from exposure to detrimental environmental factors or generalist predators increases with time. Immature development of the parasitoid in its host only required 7 days: eggs hatched within $24 \mathrm{~h}$, the first instar larva required 2 days, the second instar larva needed 3 days, and the third instar larvae exited the host and pupated in 1 day, at $27 \pm 1{ }^{\circ} \mathrm{C}, 60-80 \%$ relative humidity and a 12:12-h (long day) photoperiod. The development of the parasitized hosts was disrupted. When the parasitoid larvae finished development, the body weights of host larvae were significantly reduced regardless of which host instar was parasitized. Our results suggest that $M$. bicoloratus has considerable potential as a biological control agent for S. litura.
\end{abstract}

Key words: biological control, cephalic skeleton, Microplitis bicoloratus, oviposition, development, Spodoptera litura

\section{Introduction}

The cotton leafworm, Spodoptera litura (Fabricius), is a polyphagous insect pest widely distributed throughout the subtropical and temperate 
regions of Asia and Oceania. In China, extensive geographic areas are subject to attack by $S$. litura, resulting in serious economic losses for vegetables, ornamental plants, rice, and fruit. S. litura multicapsid nucleopolyhedrovirus (SpltMNPV) has been successfully applied on these crops on a large scale as a commercial biological insecticide (Chen et al. 1998; Pang 1998). However, one limitation to the application of the baculoviruses as a biocontrol agent is that their killing speed is relatively slow (Pang, 1994). Additionally, the uses of genetically engineered baculovirus strains have been limited to pest-plant systems where releases are considered environmentally safe (Bonning and Hammock 1996; Pang et al. 2001).

The parasitoid is another important biological agent in integrated pest management programs. It has generated a great deal of interest because of an ability to suppress pest populations to low densities. Although $S$. litura larvae in China are attacked by at least 31 species of parasitoids belonging to six families (Luo et al. 2004), a long history of extensive pesticide use has reduced these populations to the point where discovery in the field is rare. Unfortunately, none of these species have been successfully mass reared for commercial release in the field.

In May of 2003, a $S$. litura larval parasitoid was collected in a peanut field in Yangchun, Guangdong Province in China. This parasitoid was confirmed to be a new species of Microplitis Förster from China (Hymenoptera: Braconidae: Microgastrinae), described, and subsequently named Microplitis bicoloratus Chen (Chen et al. 2004). An examination of the ovary structure of $M$. bicoloratus females revealed that the parasitoid is pro-ovigenic (all eggs are eggs fully developed upon adult emergence) (Luo et al. 2005). In this report we discuss $M$. bicoloratus oviposition, immature development, rearing procedures, and potential for the biological control of S. litura.

\section{Materials and methods}

\section{Insect cultures}

Hosts A $S$. litura colony was reared in round plastic containers (diameter: $10 \mathrm{~cm}$; depth: $4.5 \mathrm{~cm}$ ) with artificial diets (after Li et al. 1998 ) at $27 \pm 1{ }^{\circ} \mathrm{C}, 60-80 \% \mathrm{RH}$, and a $12: 12$-h (long day, LD) regime. Upon completion of the larval stage, $S$. litura pupated on a sand substrate in plastic containers which were placed in a cage $(25 \times 25 \times 50 \mathrm{~cm})$ to restrain adults following eclosion. Adults mated 
following eclosion, and the females readily oviposited on sheets of paper. Eggs were collected from the paper and used to maintain the $S$. litura colony, serve as host for parasitoid colony maintenance, and provide larvae for experiments.

Parasitoids M. bicoloratus specimens were originally collected from parasitized S. litura larvae in Guangdong Province, China in 2003. The parasitoid colony was maintained on S. litura larvae reared in the laboratory; adults were also provided honey as a dietary supplement. The parasitoids mated 2-3 days following adult eclosion. In all experiments, 2- to 3-day-old mated female wasps were used.

\section{Oviposition of M. bicoloratus}

In order to understand the oviposition dynamics of the parasitoid, we conducted two experiments. In the first experiment the oviposition dynamics of $M$. bicoloratus was studied at 2-h intervals for the first $8 \mathrm{~h}$ of oviposition. A single female wasp was placed in a Plexiglas cylinder (diameter: $10 \mathrm{~cm}$; depth: $12 \mathrm{~cm}$ ) containing 20 third instar $S$. litura larvae. The groups of host larvae were exposed to the parasite for 2, 4, 6, and $8 \mathrm{~h}$ and then transferred onto an artificial diet in individual containers. At 7 days following parasitization the host larvae from which parasites did not emerge were dissected to determine if parasitoid eggs had been laid. The numbers of parasitoid cocoons and eggs that did not hatch were recorded. This experiment was replicated four times for each exposure interval.

In the second experiment the oviposition dynamics of $M$. bicoloratus was studied over a 10-day period. A single female and 40 third instar S. litura larvae were placed in a Plexiglas cylinder (as described above). After exposure for $8 \mathrm{~h}$, all $S$. litura larvae were transferred onto artificial diets in individual containers. Female wasps were provided a $20 \%$ honey solution. The test was repeated each day until the female died, or day 10, whichever came first. Data were recorded as described in the previous test. The experiment was replicated for ten female wasps.

\section{Development of M. bicoloratus}

In order to understand the development of $M$. bicoloratus in its host $S$. litura larvae, three experiments were conducted. The first experiment was to evaluate egg sizes pre-oviposition. The ovaries of three wasps were dissected. Ten eggs from each female were measured for 
length and width (widest point of the egg). All egg samples for this examination and those that follow were dissected under a binocular microscope in Pringle's solution $(154.1 \mathrm{mM} \mathrm{NaCl}, 2.7 \mathrm{mM} \mathrm{KCl}$, $14 \mathrm{mM} \mathrm{CaCl}_{2}, 22.2 \mathrm{mM}$ dextrose) (Pringle 1938) and photographed.

The second experiment aimed at evaluating egg sizes post-oviposition. Because of a known potential for insect eggs to rapidly absorb liquid - and perhaps nutrients - from the ovipositional substrate (Chapman 1975), egg sizes were evaluated $5 \mathrm{~h}$ post-oviposition. Third instar S. litura larvae were exposed to $M$. bicoloratus (ten $S$. litura larvae to each female parasite) for $1 \mathrm{~h}$ in a Plexiglas cylinder. The $S$. litura larvae were dissected after $5 \mathrm{~h}$ and the parasitoid eggs removed. The length and width of five to six eggs were then measured. This experiment was repeated three times.

The third experiment tracked the developmental rates of the parasitoid larvae. Groups of newly ecdysed third instar $S$. litura larvae were exposed to $M$. bicoloratus ( $20 \mathrm{~S}$. litura larvae to each female parasite) for $4 \mathrm{~h}$ in a Plexiglas cylinder. This approach minimized any problems with superparasitism. Cohorts of 50 host larvae were dissected daily for 1-7 days post-parasitization, and parasitoid embryos and larvae were removed. The length and width of three to four parasitoid embryos (when present) were measured and recorded. Parasitic hymenoptera have reduced or absent heads, and the soft tissue is too variable for reliable morphological measurements (Rocha et al. 2004), but a cephalic skeleton is present that increases in width both during and between instars. Consequently, the cephalic skeletons were measured at the widest point for three to four parasite larvae per cohort. The appearance of teratocytes (Dahlman and Vinson 1993) has been associated with the presence of endoparasites. The occurrence of these structures were also recorded in this study. This experiment was repeated three times for a total of 150 larval dissections for each of 7 days following parasitization.

\section{Disruption of host development}

In order to assess the disruption in the development of the parasitized host, two experiments were conducted. The first experiment examined the developmental effects of parasitization. Because larger Spodoptera sp. larvae typically cause exponentially more damage than smaller larvae $(95 \%$ of the food is consumed in the last two instars; Smits et al. 1987), the reduction in the growth rate of the parasitized hostthat can be ascribed to parasitoid attack can have significant implications for crop damage. Newly ecdysed third instar $S$. litura larvae were divided 
into two groups: one group of larvae was exposed to $M$. bicoloratus as described previously and the other group was used as the non-parasitized control. All larvae were provided an artificial diet throughout the duration of the experiment. Head capsule widths of three to five parasitized host larvae and non-parasitized host larvae were measured, and the developmental stage (instars) was recorded daily until the parasitoids pupated. This experiment was replicated three times. Insect development was mathematically evaluated using the Growth Index (GI) (Zhang et al. 1993).

The second experiment was to assess the effects of parasitism on $S$. litura larval weight. Groups of S. litura larvae were parasitized for $4 \mathrm{~h}$ (as described previously, $20 \mathrm{~S}$. litura larvae to each female parasite) in the second, third, and fourth instars. This strategy produced at least five to seven parasitized larvae per group. A second group of larvae in each instar was not parasitized as a control. All larvae were then individually placed in containers containing an artificial diet. Body weights were measured daily for 5 days post-parasitization. A minimum of 18 larvae were evaluated for the controls as well as 18 parasitized larvae in each of the instars tested ( $n>108$ larvae).

\section{Statistical analysis}

All data analyses were performed using SPSS 12.0 for Windows (SPSS, Chicago, Ill.2003). Analysis of variance using one-way ANOVA was performed for the count data. Where appropriate, treatment means were separated using the Student-Newman-Keuls (SNK) test. Egg size data were compared by independent-sample $t$-test analysis.

Insect development was characterized using the GI introduced by Zhang et al. (1993). GI values were calculated as:

$$
\mathrm{GI}=\frac{\sum_{i=1}^{\mathrm{i}_{\max }}\left[n(i) \times i+\sum_{i=1}^{\mathrm{i}_{\max }}[n(i) \times(i-1)]\right]}{N \times i_{\max }}
$$

where $i_{\max }=3$ or 5 , the highest attainable instar of the larvae by day 3 or day 7 post-parasitization, respectively. The value $n_{(i)}=$ the number of insects alive at stage $i, n_{(i)}^{\prime}=$ the number of insects dead at stage $i$, and $N=$ the total number of insects tested. This index provides an indication of the developmental stage reached by the cohort of test insects at the completion of the test, with values approaching one indicating that a large proportion reached the maximum larval instar and values near zero indicating that few insects survived or 
developed beyond the second instar. GI means of control and parasitized larvae at days 3 and 7 post-parasitization were separated using ANOVA, with no transformations required (SuperANOVA 1991).

\section{Results}

\section{Ovipositional performance of M. bicoloratus}

In the 8-h oviposition experiments, $M$. bicoloratus oviposited significantly more eggs during the first and second 2-h intervals than during third and fourth periods $\left(F_{3,72}=22.6, p<0.01\right)$ (Figure 1$)$. The numbers of eggs deposited in the first and second intervals were not significantly different; similarly, there were no significant differences between the numbers of eggs oviposited during the third and fourth time intervals.

In the 10-day oviposition experiments, M. bicoloratus parasitoids laid significantly more eggs on the first day than on any of the other 9 days that followed $\left(F_{9,57}=10.4, p<0.01\right)$ (Figure 2), with nearly one third of the total number of eggs being oviposited on the first day [total egg production (mean $\pm \mathrm{SE})=50.2 \pm 7.8$ per female]. Although the females oviposited for up to 10 days, over $50 \%$ of the eggs were laid within the first 3 days. There were no significant differences $(p>0.05)$ in the mean numbers of eggs produced daily from day 2 to day 10 .

\section{Development of M. bicoloratus}

Eggs were translucent white, elongate, rounded at both ends, and slightly curved (Figure 3A). The length and width of eggs pre-oviposi-

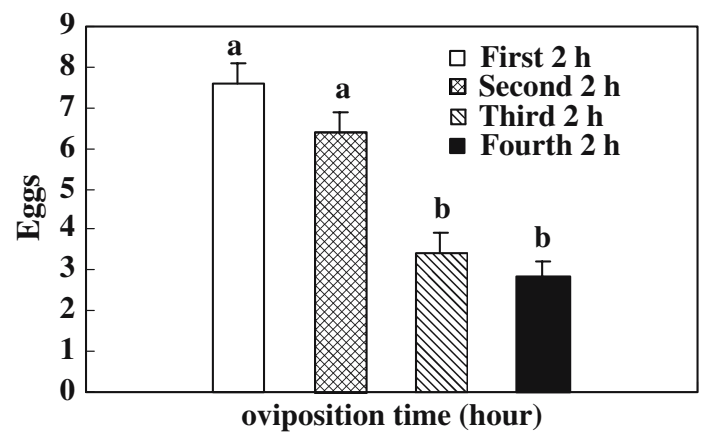

Figure 1. Number of eggs (mean $\pm \mathrm{SE}$ ) laid by M. bicoloratus in each of 2-h intervals for the first $8 \mathrm{~h}$ of oviposition. Mean values with the same letters are not significantly different each other (SNK test; $p>0.05$ ) 


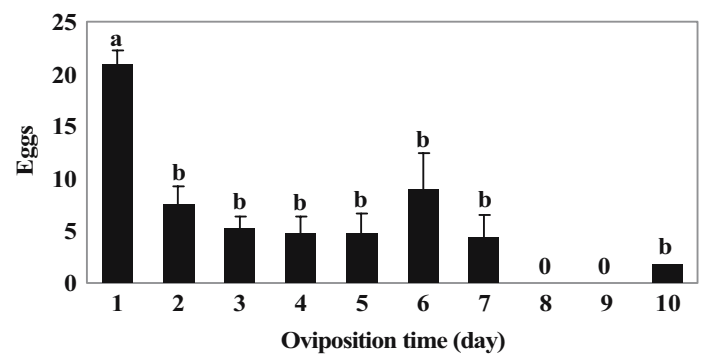

Figure 2. Number of eggs (mean \pm SE) laid by $M$. bicoloratus over a 10-day period. Mean values with the same letters are not significantly different from each other (SNK test; $p>0.05$ )
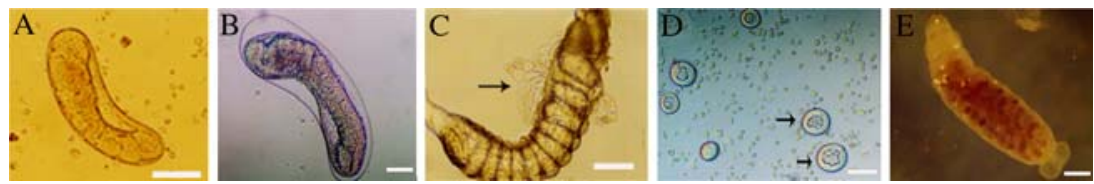

Figure 3. Egg, embryo, larva and teratocytes in hemocoel of the host $S$. litura larvae parasitized by $M$. bicoloratus. A 5-h-old egg, B embryo, C first-instar larva (arrow indicates serosa cell), $\mathbf{D}$ teratocytes (arrow), $\mathbf{E}$ second-instar larva. Bar: (A, C) $50 \mu \mathrm{m} ;(\mathbf{B}, \mathbf{D}, \mathbf{E}) 20 \mu \mathrm{m}$

tion were $194 \pm 3.3$ and $43.7 \pm 1.3 \mu \mathrm{m}$ (mean $\pm \mathrm{SE}, n=30$ ), respectively. Egg length and width at $5 \mathrm{~h}$ post-oviposition were $209 \pm 6.0$ and $70.6 \pm 3.0 \mu \mathrm{m}(n=17)$, respectively. While egg length was not significantly different between eggs pro-oviposition and eggs $5 \mathrm{~h}$ postoviposition ( $t$-test, $p>0.05$ ), egg width was significantly different between eggs pro-oviposition and eggs $5 \mathrm{~h}$ post-oviposition ( $t$-test, $p<0.01)$. These results indicate that eggs of $M$. bicoloratus rapidly absorb liquid - and perhaps nutrients - from the hemocel of host $S$. litura larvae. The egg stage lasted approximately $24 \mathrm{~h}$. Late in this period the embryo (length: $377.3 \pm 13.7 \mu \mathrm{m}$; width: $88.6 \pm 3.9 \mu \mathrm{m}$; $n=11$ ) was clearly visible (Figure $3 \mathrm{~B}$ ).

$M$. bicoloratus required 7 days to complete three larval instars and pupate at $27 \pm 1{ }^{\circ} \mathrm{C}, 60-80 \% \mathrm{RH}$, and a 12:12-h photoperiod. One day after oviposition, the larvae eclosed but remained partially surrounded by clinging masses of serosa cells (Figure 3C). First instar larvae remained in this stage for up to $48 \mathrm{~h}$.

First instar larvae grew slowly. The width of the cephalic skeleton was not significantly larger on the second day than on the first day (Table 1), neither did the length of the larva significantly differ 
KAIJUN LUO ET AL.

Table 1. Larval development of M. bicoloratus in its host S. litura

\begin{tabular}{llll}
\hline $\begin{array}{l}\text { Developmental } \\
\text { times (days) }\end{array}$ & Instar & \multicolumn{2}{l}{ Larval development parameters ${ }^{\mathrm{a}}$} \\
\cline { 3 - 4 } & & Length of larva $(\mu \mathrm{m})$ & Width of cephalic skeleton $(\mu \mathrm{m})$ \\
\hline 2 & 1 & $486.4 \pm 24.6 \mathrm{a}$ & $100.0 \pm 0$ \\
3 & 1 & $577.3 \pm 13.3 \mathrm{a}$ & $129.6 \pm 3.0 \mathrm{a}, \mathrm{b}$ \\
4 & 2 & $1154.2 \pm 40.1 \mathrm{~b}$ & $183.3 \pm 7.1 \mathrm{~b}, \mathrm{c}$ \\
5 & 2 & $1425.0 \pm 97.8 \mathrm{~b}$ & $200.0 \pm 6.2 \mathrm{c}$ \\
6 & 2 & $2589.1 \pm 192.7 \mathrm{c}$ & $465.5 \pm 40.1 \mathrm{~d}$ \\
7 & 3 & $3280.0 \pm 156.9 \mathrm{~d}$ & $626.7 \pm 23.8 \mathrm{e}$ \\
\hline
\end{tabular}

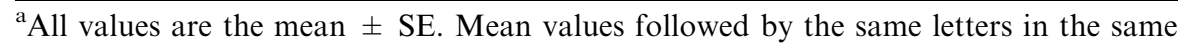
column are not significantly different from each other (SNK test, $p>0.05$ )

between day 1 and day 2. Teratocytes derived from serosa cells (Figure 3D) were observed in the host hemolymph by day 2 .

Second instars were readily distinguishable from first instars by the presence of a ring-like structure at the anterior part of the anal vesicle. The second instar stage lasted approximately $72 \mathrm{~h}$ (Figure 3E), and during this period there was a significant increase in the length of the larvae and the width of the cephalic skeleton width (Table 1).

The third instar stage lasted only $24 \mathrm{~h}$. The length of the larvae and the width of the cephalic skeleton were significantly larger for the third instars than for the second instars $\left(F_{5,63}=102.7, p<0.01\right.$; $F_{5,63}=124.6, p<0.01$, respectively) (Table 1 ). Third instars did not appear to feed substantially on the host, rather they chewed an emergence hole in the host, exited, and spun a cocoon immediately beside the host. The host larvae died soon afterwards.

\section{Effects of the parasitism on development of host S. litura}

At 3 days post-parasitization, there were no developmental differences between control and parasitized larvae $(\mathrm{GI}=1.0$ for control and 1.0 for parasitized larvae). However, at 4 days following parasitization, the development of the parasitized host larval was significantly arrested compared to that of the non-parasitized larvae. Parasitized third instar $S$. litura only molted once, as measured by a change in head capsule size (Table 2), while non-parasitized larvae molted up to three times (Table 2). By 7 days post-parasitization, the GI indicated significant differences in development between the control larvae and their parasitized counter parts, with the former having an average 
Table 2. Head capsule width of S. litura larvae parasitized by $M$. bicoloratus compared with non-parasitized control larvae

\begin{tabular}{|c|c|c|c|c|}
\hline \multirow{2}{*}{$\begin{array}{l}\text { Day following } \\
\text { parasitization }\end{array}$} & \multicolumn{2}{|c|}{ Parasitized larvae $^{\mathrm{a}}$} & \multicolumn{2}{|c|}{ Non-parasitized control $^{\mathrm{a}}$} \\
\hline & Instar & $\begin{array}{l}\text { Head capsule } \\
\text { width }(\mu \mathrm{m})\end{array}$ & Instar & $\begin{array}{l}\text { Head capsule } \\
\text { width }(\mu \mathrm{m})\end{array}$ \\
\hline 1 & 3 & $500.0 \pm 13.5 \mathrm{a}$ & 3 & $500.0 \pm 0 \mathrm{a}$ \\
\hline 2 & 3 & $500.0 \pm 0 \mathrm{a}$ & 4 & $884.6 \pm 60.8 \mathrm{~b}$ \\
\hline 3 & 4 & $1140.0 \pm 40.0 \mathrm{c}$ & 4 & $1200.0 \pm 0 \mathrm{c}$ \\
\hline 4 & 4 & $1100 \pm 24.5 \mathrm{c}$ & 5 & $1440.0 \pm 98.0 \mathrm{~d}$ \\
\hline 5 & 4 & $1159.1 \pm 21.1 \mathrm{c}$ & 5 & $1785.0 \pm 15.0 \mathrm{~d}$ \\
\hline 6 & 4 & $1140.0 \pm 24.5 \mathrm{c}$ & 5 & $1800.0 \pm 0 \mathrm{~d}$ \\
\hline 7 & 4 & $1140.0 \pm 24.5 \mathrm{c}$ & 6 & $2040.0 \pm 98 \mathrm{e}$ \\
\hline
\end{tabular}

${ }^{a}$ All values are the mean \pm SE. Mean values followed by the same letters in the same column are not significantly different from each other (SNK test, $p>0.05$ )

GI of $0.877 \pm 0.046$ and the latter a GI of $0.560 \pm 0.040\left(F_{1,4}=26.78\right.$, $p=0.007)$.

Upon completion of immature development by the parasitoids, the body weights of the host larvae were significantly lower than those of the non-parasitized control larvae. For S. litura larvae parasitized in the second instar, no differences in body weights were detected until 5 days following oviposition, when the body weights of the parasitized host larvae were significantly lower than those of non-parasitized control larvae $\left(F_{9,200}=54.86, p<0.01\right)$ (Figure 4). For $S$. litura larvae parasitized in the third instar, significant reductions in body weight were observed at 3 days following oviposition $\left(F_{9,195}=220.70, p<0.01\right)$ (Figure 4$)$. Similarly, $S$. litura larvae parasitized in the fourth instar developed significant reductions in body weights compared to the control larvae at 4 days following oviposition $\left(F_{9,220}=115.65, p<0.01\right)$ (Figure 4$)$. Final host weights were consistent with the timing of oviposition: host weights were least when oviposition occurred in the second instar and greatest when oviposition occurred in the fourth instar.

\section{Discussion}

M. bicoloratus immature development was rapid, requiring only 7 days to complete all three instars at $27 \pm 1^{\circ} \mathrm{C}$. The morphology of the first instar was very different from that of the other two instars. This was not surprising as similar results have been reported in Microplitis 


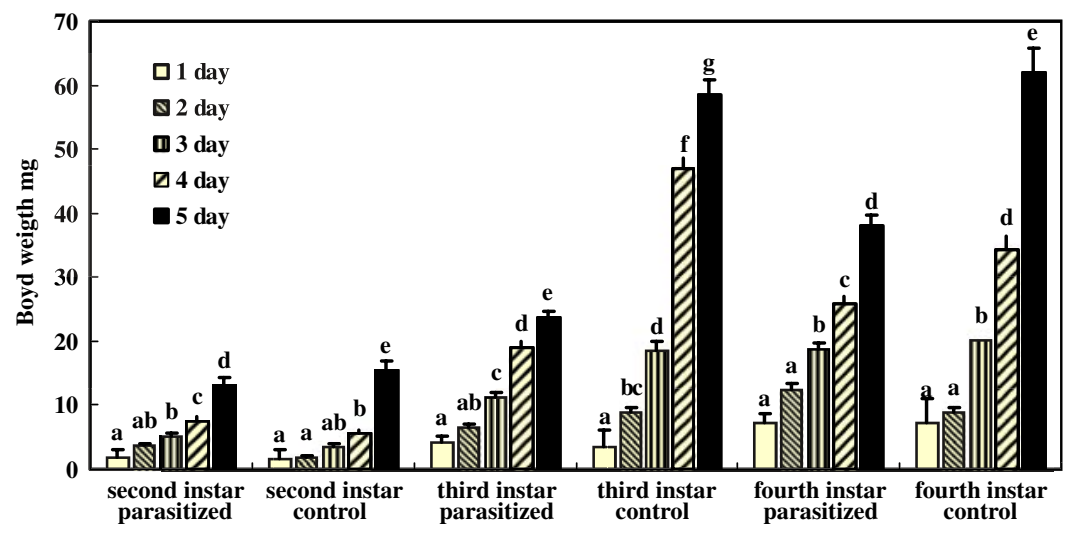

Figure 4. Body weight (mean $\pm \mathrm{SE}$ ) of second to fourth instar S. litura larvae parasitized by $M$. bicoloratus at 1-5 days post-parasitization compared with non-parasitized, control larvae. Mean values with the same letter in the same instar are not significantly different from each other (SNK test; $p>0.05$ )

rufriventris, a solitary larval endoparasitoid of Spodoptera littoralis (Hegazi and Fuhrer 1985) and Chelonus inanitus, a solitary egg-larval endoparasitoid of S. littoralis (Grossniklaus-Bürgin et al. 1994).

Gauld and Hanson (1995) reported that many endoparasitoids are pro-ovigenic, which has been shown to be the case for $M$. bicoloratus as well (Luo et al. 2005). In the present study, M. bicoloratus females oviposited on the third larvae of $S$. litura for up to 10 days, but a high proportion of eggs were laid on the first day (approximately $30 \%$ ), with over $50 \%$ laid within the first 3 days. This rapid oviposition rate increases the potential for biological suppression of host populations because the likelihood of mortality for the parasites from exposure to detrimental environmental factors or generalist predators increases with time. Euplectrus maternus, a gregarious parasitoid of the larvae of the fruit-piercing moth, Eudocima (Othreis) fullonia, was observed to continuously lay eggs on the second larvae of E. fullonia for up to 30 days, but the greatest number of eggs were laid during the first week after exposure (Muniappan et al. 2004). The ability to rapidly oviposit a large proportion of the total egg load would also be of benefit in mass-rearing parasitoids.

In agricultural settings, a potential disadvantage of koinobiont parasitoids (where host larvae continue to develop following oviposition) as compared to idiobionts (where host larvae are paralyzed during oviposition) is that the host larvae will continue to feed on the crop plant (Gauld and Hanson 1995). Many parasitoids actively use different strategies in sequence, with the earlier instars of the host showing 
no symptoms of disruption, whereas the final instar(s) experience disruption of feeding activity, molting, and metamorphosis (Beckage and Gelman 2004). The development of S. litura larvae parasitized by $M$. bicoloratus was arrested. The GI analysis indicated that the parasitized host larvae only reached about $55 \%$ of their overall growth potential. S. litura larvae parasitized in the second and third instars only developed by one additional instar, thereby substantially limiting their potential for crop damage. Elimination of the fifth and sixth (and sometimes seventh) instars would most likely result in an overall reduction in feeding of at least 95\% (Smits et al. 1987).

Lawrence (1986) divided parasitoids into two categories on the basis of their interactions with their respective host: regulators and conformers. The regulators evoke developmental disruption of the host (usually via endocrine pathways), whereas the conformers do not redirect the host developmental program. Our studies indicate that $M$. bicoloratus is a solitary endoparasitoid that falls in the 'regulator' category. Typical 'regulator' host-controlling factors include polydnaviruses, venoms, teratocytes, and the parasitoid larvae itself (Dahlman and Vinson 1993; Beckage 1998; Rana et al. 2002). For $M$. bicoloratus, we were able to confirm the presence of teratocytes.

Based on our laboratory experiments, M. bicoloratus deserves additional study for its potential as a biological control agent for $S$. litura. Future studies should not only include independent field trials but also experiments designed to determine the compatibility of M. bicoloratus and SpltMNPV against $S$. litura in China.

\section{Acknowledgements}

This research was supported by the National Major Basic Research Project ('973') of China (G2000016209) and Open-funding of the State Key Laboratory of Biocontrol in Sun Yat-sen University (0404). The authors gratefully acknowledge Dr. Jiahua Chen for his help with the identification of the wasp.

\section{References}

Beckage, N.S., 1998. Modulation of immune responses to parasitoids by polydnavirus. Parasitology 116(Suppl.), S57-S64.

Beckage, N.S. and D.B. Gelman, 2004. Wasp parasitoid disruption of host development: Implications for new biologically based strategies for insect control. Аnпи. Rev. Entomol. 49: 299-330. 


\section{KAIJUN LUO ET AL.}

Bonning, B.C. and B.C. Hammock, 1996. Development of recombinant baculovirused for insect control. Annu. Rev. Entomol. 41: 191-210.

Chapman, R.F., 1975. The insects, structure and function. American, New York.

Chen, J.H., Q.E. Ji and D.B. Song, 2004. A new species of Microplitis Förster from China (Hymenoptera: Braconidae: Microgastrinae). Entomotog. J. East China 13: 1-5.

Chen, Q.J., Y. Pang and G.H. Li, 1998. Spopdoptera litura nucleopolyhedrovirus insecticide: Chongwen-I. J. Wuhan Univ. 44: 183.

Dahlman, D.L. and S.B. Vinson, 1993. Teratocytes: developmental and biochemical characteristics. In: N.E. Beckage, S.N. Thompson and B.A. Federici (eds.), Parasites and pathogens of insects. 1Academic Press, San Diego. pp. 145-165.

Gauld, I. D. and P.E. Hanson, 1995. Life history strategy: idiobionts and koinobionts. In: D.L.J. Quicke, (ed.), Parasitic wasps. Cambridge University Press, Cambridge. pp. 68-71.

Grossniklaus-Bürgin, C., T. Wyler, R. Pfister-Wilhelm and B. Lanzrein, 1994. Biology and morphology of the parasitoid Chelonus inanitus (Braconidae, Hymenoptera) and effects on the development of its host Spodoptera littoralis (Noctuidae, Lepidoptera). Invertebr. Reprod. Dev. 25: 143-158.

Hegazi, E.M. and E. Furhrer, 1985. Instars of Microplitis rufiventris (Hym: Braconidae) and their relative developmental speed under different photoperiods. Entomophaga 30: 231-243.

Lawrence, P.O., 1986. Host-parasite hormonal interactions: an overview. J. Insect Physiol. 32: 298-298.

Li, G.H., Q.J. Chen and Y. Pang, 1998. Studies of artificial diets for the beet armyworm, Spodoptera exigua. Acta Sci. Nat. Univ. Sun Yat-Sen 4: 1-5.

Luo, K.J., D.X. Gu, G.R. Zhang and Z.Q. Cheng, 2004. Parasitoids of four noctuidae pests in cruciferous vegetable. Chin. J. Biol. Control 20: 211-214.

Luo, K.J., D.X. Gu, G.R. Zhang and Z.Q. Cheng, 2005. Ovary structures of two parasitic wasps Microplitis bicoloratus and Diglyhus isaea. Entomol. Knowledge 42: 69-70.

Muniappan, R., J. Bamba, J. Cruz and G.V.P. Reddy, 2004. Biology, rearing and field release on Guam of Euplectrus maternus, a parasitoid of the fruit-piercing moth, Eudocima fullonia. BioControl 49: 537-551.

Pang, Y., 1994. Viral diseases. In: Z.L. Pu, (ed.), Insect pathology. Guangdong Science and Technology Press, Guangzhou. pp. 85-216.

Pang, Y., 1998. Study and application of insect pathogens. In: J.Z. Bao and D.X. Gu (eds.), Biological control in China. Shanxi Science and Technology Press, Taiyuan. pp. 368-494.

Pang, Y., Zh.H. Hu and K. Yang, 2001. Recombinant baculoviruses. In: D.F. Huang and M. Lin (eds.), Agricultural microbes. Science and Engineered Technology Press, Beijing. pp. 271-315.

Pringle, J.H.W., 1938. Proprioception in insects. J. Exp. Biol. 15: 101-103.

Rana, R.L., D.L. Dahlman and B.A. Webb, 2002. Expression and characterization of a novel teratocyte protein of the Branconid, Microplitis croceipes (Cresson). Insect Biochem. Mol. Biol. 32: 1507-1516.

Rocha, K.L., T. Mangine, E.J. Harris and P.O. Lawrence, 2004. Immature stages of Fopius arisanus (Hymenoptera: Braconidae) in Bactrocera dorsalis (Diptera: Tephritidae). Fla. Entomol. 87: 164-168.

Smits, P.H., M.C. van Velden, M. van de Vrie and J.M. Vlak, 1987. Feeding and dispersion of Spodoptera exigua larvae and its relevance for control with a nuclear polyhedrosis virus. Entomol. Exp. Appl. 43: 67-72. 
DEVELOPMENT OF MICROPLITIS BICOLORATUS ON SPODOPTERA LITURA

SPSS Inc., (2003). SPSS 12.0 for Windows, user's guide. SPSS Inc., Chicago.

SuperANOVA, 1991. Abacus concepts. Berkeley, Calif.

Zhang, M., S.K. Chadhuri and I. Kubo, 1993. Quantification of insect growth and its use in screening of naturally occurring insect control agents. J. Chem. Ecol. 19: $1109-1118$. 